\title{
COMPUTER ASSISTED CIRCULATION CONTROL AT HEALTH SCIENCES LIBRARY SUNYAB
}

Jean K. MILLER: Associate Health Sciences Librarian for Circulation and Dissemination

A description of the circulation system which the Health Sciences Library at the State University of New York at Buffalo has been using since October 1970. Features of the system include automatic production of overdue, fine, and billing notices; notices for call-in of requested books; and book availability notices. Remote operation and processing on the IBM 360/40 and CDC 6400 computer are accomplished via the Administrative Terminal System (ATS) and Terminal Job Entry (TJE). The system provides information for management of the collection and improved service to the user.

\section{INTRODUCTION}

The Health Sciences Library of the State University of New York at Buffalo (SUNYAB) serves the teaching, research, and clinical programs of the five schools of Health Sciences at the University-Medicine, Dentistry, Pharmacy, Nursing, Health Related Professions-as well as the Department of Biology. It is the biomedical resource library for the five teaching hospitals affiliated with SUNYAB and for the health professionals within the nine counties of the Lakes Area Regional Medical Program.

Service demands had increased steadily since 1961 with the incorporation of the university within the State of New York. This was apparent in the Circulation Department where statistics indicated a 21 percent increase in the circulation of materials between FY 1967/68 and 1968/69. The circulation system in use was inefficient and time-consuming for both the user and the clerical staff. The user was required to fill out a charge card for each book, giving his name, address, and status; and the title, author, year of publication, volume, copy number, and call number of the book. The card 
was stamped with the due date and filed alphabetically by main entry. Problems resulted from illegible handwriting, selection of incorrect main entry, and incorrect filing. Control of library materials was inadequate.

The system to be described was adopted following consideration of the requirements of an effective system of circulation control and of the resources available to the library. Planning for the development and implementation of the automated circulation system began in the fall of 1969 . Funding was provided by a Medical Library Resource Grant and the Office of the Provost of Health Sciences of SUNYAB. System design began in February 1970; programming was accomplished during June and July; implementation started in August; and the system was operational in October 1970. Costs of operation have been provided by the University Libraries of SUNYAB since April 1971.

\section{COMPUTER FACILITIES}

The Health Sciences Library shares the facilities provided by the Department of Computer Services on campus. The current installation is an IBM $360 / 40 \mathrm{H}$ with an eight-disk drive 2319 unit, six magnetic tape devices, card read and punch unit, and a 1100 line-per-minute printer. It includes a 2703 telecommunications unit supporting forty 2741 terminals and a 2701 unit with parallel data adapter unit interfacing a channel-to-channel adapter to a CDC 6400 computer. The IBM Operating System, SCOPE 3.2.0 version 1.1 , is used.

\section{PROCESSING}

The library's circulation system was designed to use the Administrative Terminal System (ATS) and Terminal Job Entry (TJE) for remote operation and processing on the IBM $360 / 40$ and CDC 6400 computers. Programs are written in FORTRAN for CDC 6400-6500-6600 (version 2.3). The program modules comprising the circulation system require from $1 \mathrm{~K}$ to $60 \mathrm{~K}$ and from 0 to 2 tape units for processing. ATS documents are used rather than punched card decks as program and data input media.

The system incorporates several large data bases which are updated at regular intervals. A file of current circulation transactions (80 characters per record) is maintained on both magnetic tape and in ATS storage. This file is merged daily with new transactions. Names and addresses of university personnel and students are maintained on magnetic tape. A file of inactive circulation records ( 50 characters per record) is also maintained on tape. Other smaller files are stored in ATS and are updated daily and/or weekly. No permanent disk storage is used.

Input of data and programs is made from the IBM 2741 terminal located in the Circulation Office of the library. Data are entered daily by the clerical staff via the ATS terminal. Storage, retrieval, and text editing are performed as required. Processing of data is initiated by the library staff. A properly sequenced assemblage of ATS documents consisting of data and pro- 
gramming instructions (TJE input file) is input from the IBM 2741 terminal. This input file is submitted through TJE for execution on the CDC 6400 computer. The data are processed in accordance with the specific job command entered at the terminal.

After processing, the output is stored as a single ATS document. In some instances, the clerical staff divides the ATS stored output into discrete output files for storage and subsequent use. Selected segments of the output (notices, save lists, etc.) are produced in hard copy format and delivered to the library by the Computer Center (Figure 1).

\section{HSCCIRC SYSTEM}

The Health Sciences Library Circulation System (HSCCIRC) provides:

1. A file (Query File) of all monographs off the shelves which includes a record of:

a. Books charged out.

b. Books on interlibrary loan.

c. Books on reserve.

d. Books at the bindery.

e. Books on the "hold shelf" which have been returned upon the request of another patron.

f. Books on the "new book shelf."

g. Books which have been declared lost and are in the process of being replaced.

2. Overdue notices to all borrowers.

3. Billing notices to students for those books not returned after a second overdue has been sent.

4. A file (Fine File) indicating the amount owed by individual students for overdues.

5. Fine notices to students if an overdue book is returned but the fine is not paid.

6. Notices to users having books requested by other patrons.

7. Hold shelf notices alerting library personnel to those books which have been reserved for library patrons.

8. Book availability notices to users who have made "save" requests.

9. A file (History File) containing records of inactive transactions.

10. Daily and cumulative (fiscal year-to-date) statistics of the transactions.

The foregoing lists the information which the system provides on a routine basis. Other modules of the system permit access to additional information as required. For example, lists may be prepared of books currently in circulation to interlibrary loan, on reserve, or at the bindery. These lists are used by the staff involved in processing these materials and may be updated at their request. 


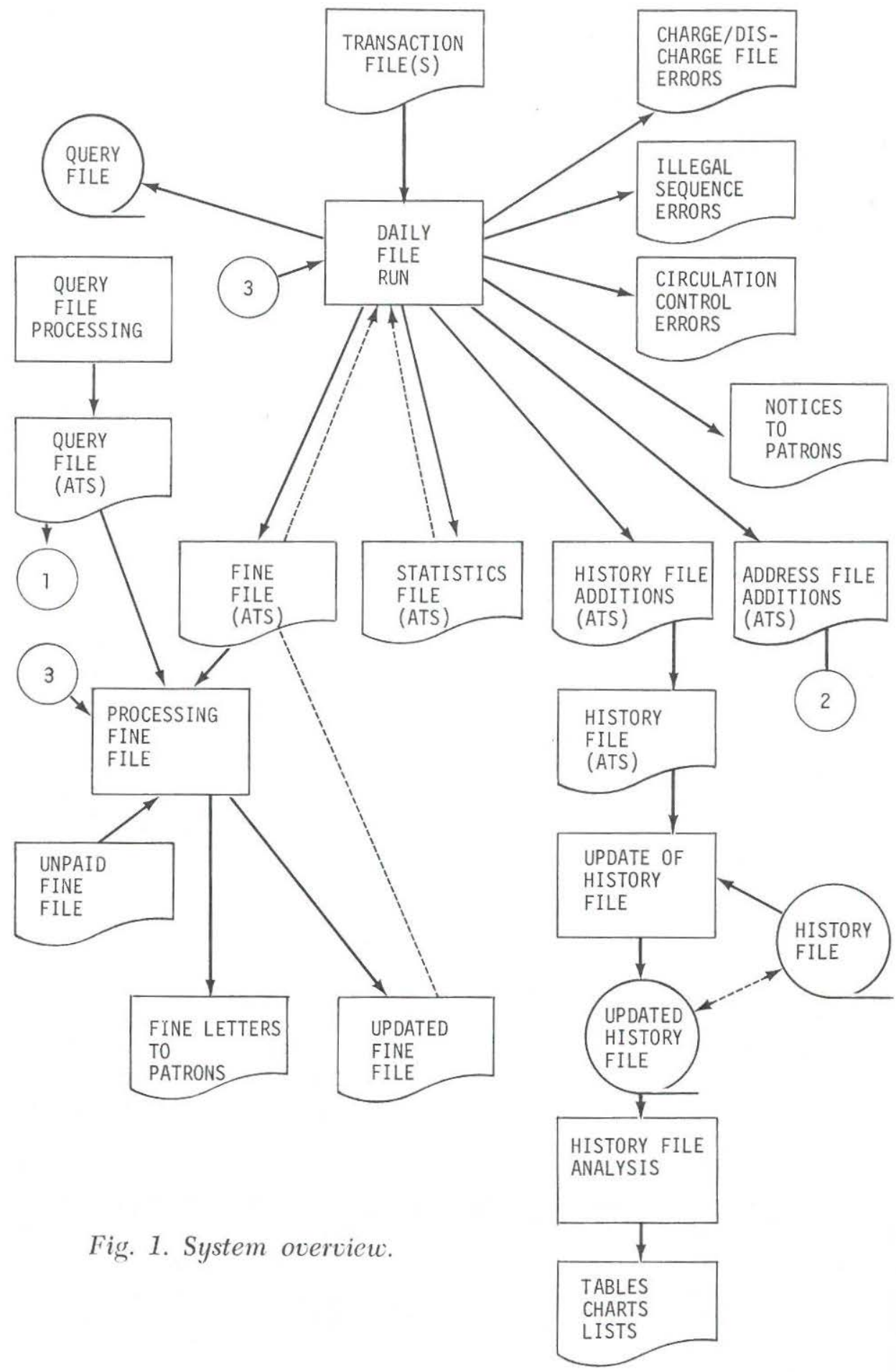




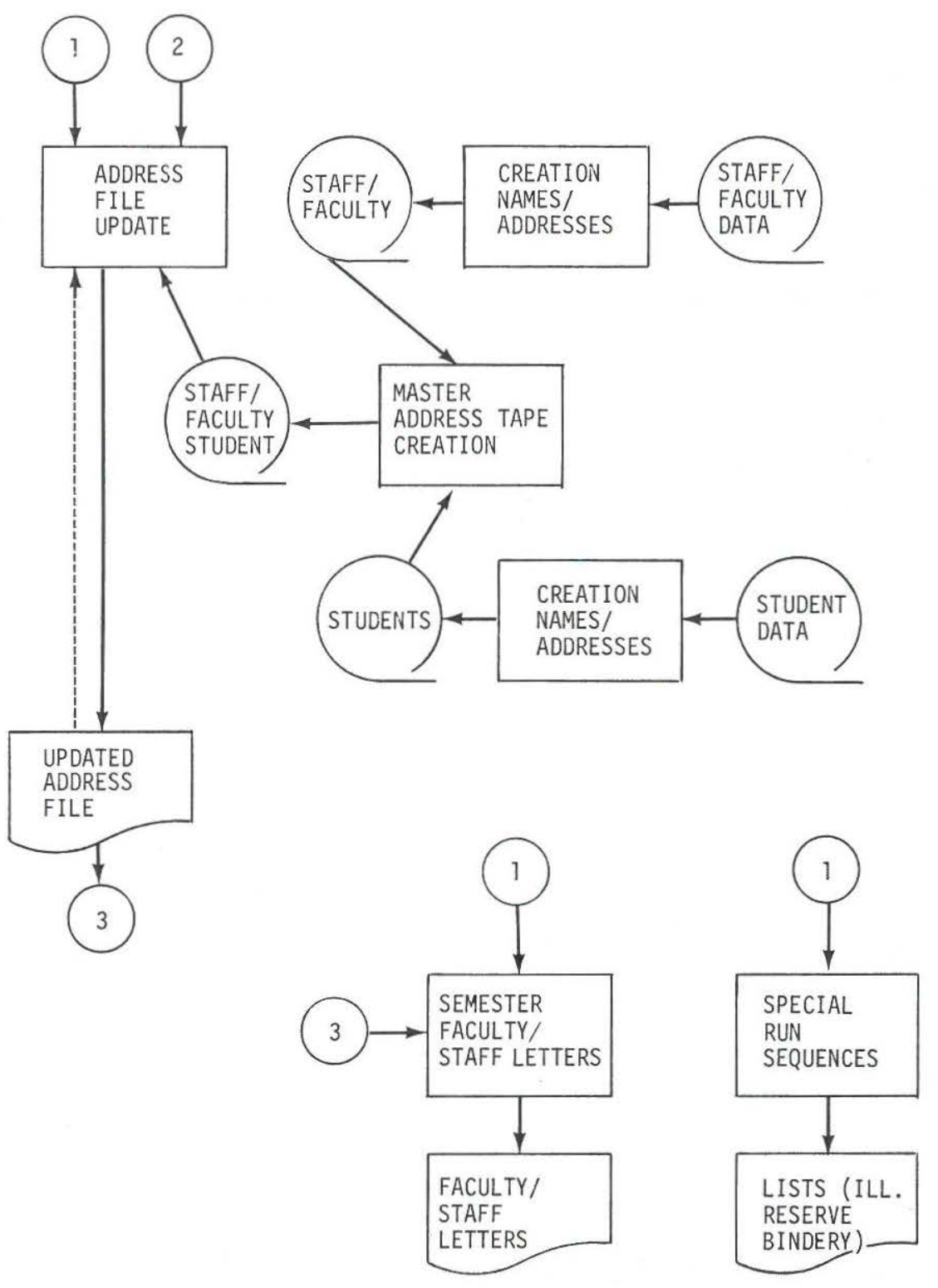


The History File is analyzed quarterly. The analysis provides a statistical breakdown, by user categories, of the transactions which occurred since the last analysis. The total number of charges, renewals, and save requests for each of the five user categories are tallied. The call numbers of the books borrowed by members of each user category are listed. Multiple charges of the same book are incremented and recorded.

This information on book usage and borrowing patterns assists in library management decisions. It is possible to identify high usage of specific volumes or subject areas and to determine whether the demand is from the faculty, staff, or graduate or undergraduate student body. Records of heavy demand and multiple save requests aid in decisions to purchase additional copies of a monograph.

At the end of each semester, faculty/staff letters are prepared and mailed. Each notice lists the call number and due date for overdue books currently charged to the faculty or staff member. The notice requests return of the book $(s)$ before the beginning of the next semester.

Statistics generated by the system (Figure 2) are used in the preparation of monthly, quarterly, and annual reports. They have been used as a basis for decisions on policy such as that resulting in a change in the length of the circulation period in April 1971. Subsequent statistics have been used to evaluate such changes.

In addition, the system permits rapid, easy consultation of the Query File to detect the location of any book off the shelves. This is accomplished through use of the printed Query File (Figure 3) which is arranged in call number sequence. It contains one line of information for each transaction

\begin{tabular}{|c|c|c|}
\hline & 42572 & Year to date \\
\hline New Chrgs & 112 & 2225 \\
\hline Holds & 5 & 185 \\
\hline Spcl chrgs (ILL) & 5 & 85 \\
\hline Spcl chrgs (BND) & 0 & 48 \\
\hline Spcl chrgs (RES) & 1 & 116 \\
\hline Renewals & 12 & 308 \\
\hline Save requests & 3 & 74 \\
\hline Recall letters & 2 & 63 \\
\hline Hold letters & 3 & 99 \\
\hline Books overdue & 48 & 1230 \\
\hline lst overdue & 0 & 773 \\
\hline 2nd overdue & 0 & 364 \\
\hline Bills & 0 & 122 \\
\hline Lost books & 2 & 61 \\
\hline Discharges & 173 & 2837 \\
\hline Discharges (hld shlf) & 5 & 154 \\
\hline
\end{tabular}

Fig. 2. Circulation statistics. 


*QL696/P2L27/1
*QL696/P2L27/1
*QL697/G4/1966/1
*QL697/G4/1966/1
*QL698//H25/1
*QL698/J3/1953/1
*QL698/S78/1965/1
*QL698/S78/1
*QL698.3/A7/1965/1
*QL703/W22/1968/V1/1
*QL706//P25/1957/1
*QL715/CC132M/1966/1
*QL731/D67F/1969/1
*QL731/D67F/1969/1
*QL731/E55/1953/1
*QL731/E55/1953/1
*QL737/C2H24/1948/1
*QL737/C2H24/1952/1
*QL737/C2H24/1966/1
*QL737/C23C7/1969/1
*QL737/C4L5/1961/1
*QL737/C7/1964/1
*QL737/M3F919K/1969/1
*QL737/M3F919K/1961/1
*QL737/P9B9/1963/1
*QL737/P9H4/V1/1953/1
*QL737/P9H4/V1/1953/1
*QL737/P9M64/1967/3
*QL737/P9S3/1965/V2/2

\begin{tabular}{|c|c|c|c|c|c|c|c|}
\hline *C10 & *T & 60772 & *D & 70772 & *p & 202319 & *U3 \\
\hline$\star \star C 51$ & $\star T$ & 71172 & $* D$ & 71872 & $\star p$ & 202319 & *U3 \\
\hline *C10 & *T & 62672 & $* D$ & 62672 & $\star p$ & 71165132 & *U1 \\
\hline *C52 & *T & 70772 & $* D$ & 71472 & $\star p$ & 71165132 & *U1 \\
\hline${ }^{*} \mathrm{C} 10$ & *T & 61972 & $\star D$ & 71972 & $\star p$ & 138551 & *U3 \\
\hline *C10 & *T & 61972 & $* D$ & 71772 & *P & 138551 & *U3 \\
\hline${ }^{*} \mathrm{C} 20$ & *T & 62372 & $* D$ & 72372 & $\star p$ & 244856 & *U2 \\
\hline${ }^{*} \mathrm{C} 10$ & *T & 61972 & *D & 71972 & $* p$ & 138551 & *U3 \\
\hline *C10 & $\star T$ & 61972 & $* D$ & 71972 & $\star p$ & 138551 & *U3 \\
\hline${ }^{*} \mathrm{C} 10$ & *T & 51172 & $\star D$ & 61172 & *p & 102714 & *U3 \\
\hline${ }^{*} \mathrm{C} 10$ & *T & 71172 & $\star D$ & 81172 & *P & 440503366 & *U4 \\
\hline${ }^{*} \mathrm{C} 10$ & *T & 70272 & $\star D$ & 80272 & $\star p$ & 180439 & *U3 \\
\hline${ }^{\star} \mathrm{C} 10$ & *T & 51872 & $\star D$ & 61872 & $\star p$ & 102714 & *U3 \\
\hline *C53 & $\star T$ & 70772 & $\star D$ & 71472 & $\star p$ & 102714 & *U3 \\
\hline${ }^{*} \mathrm{Cl}$ & $\star T$ & 51872 & $* D$ & 61872 & $\star p$ & 102714 & *U3 \\
\hline *C53 & *T & 70772 & $* D$ & 71472 & $\star p$ & 102714 & *U3 \\
\hline *C10 & *T & 50772 & $* D$ & 60772 & $* p$ & 147339 & *U2 \\
\hline${ }^{*} \mathrm{C} 60$ & *T & 42472 & $\star D$ & -0 & $* p$ & -0 & *UO \\
\hline${ }^{*} \mathrm{C} 6 \mathrm{C}$ & $\star T$ & 42472 & $* D$ & -0 & $\star p$ & -0 & *UO \\
\hline * $\mathrm{ClC}$ & *T & 62172 & $\star D$ & 72172 & $\star p$ & 175470 & *U2 \\
\hline *C6C & *T & 30172 & $* 0$ & -0 & $\star p$ & -0 & *UO \\
\hline${ }^{\star} \mathrm{Cl}$ & *T & 62272 & $* D$ & 72272 & $\star p$ & 220053 & *U3 \\
\hline${ }^{*} \mathrm{Cl}$ & *T & 60972 & $* D$ & 70972 & $\star p$ & 165872 & *U3 \\
\hline$\star{ }^{2} 5$ & *T & 71172 & $* D$ & 71872 & $\star p$ & 165872 & *U3 \\
\hline *CE & *T & 12272 & $* D$ & -0 & $\star p$ & & *UO \\
\hline${ }^{*} \mathrm{Cl}$ & *T & 51172 & $* D$ & 61172 & $\star p$ & 102714 & *U3 \\
\hline & *T & 71172 & $\star D$ & 61172 & $\star p$ & 102714 & *U3 \\
\hline$* \mathrm{Cl}$ & $\star T$ & 61572 & $* D$ & 71572 & $\star p$ & 360307268 & *U6 \\
\hline & *T & 100471 & $\star D$ & -0 & $\star p$ & 777777777 & \\
\hline
\end{tabular}

LEGEND: * Call number *C Transaction Code *T Date of transaction *D Due date or date next notice will be generated *P Patron identification number *U User category

Fig. 3. Query file.

changing the status of a book. For example, when a book is charged, the Query File contains one line of information relating to the charge. If the book becomes overdue, a second line of information is automatically generated indicating the overdue status of the book. A two-digit transaction code defines the status. The transaction code is entered as part of the input (as code 10 when charging a book); or it is generated by the system, as occurs when a book becomes overdue and initial and subsequent overdue, billing, and/or fine notices are produced (code 51,52,53,54).

This same information may be obtained through on-line query of the circulation file from the IBM 2741 terminal during the hours of operation of ATS. Access to the Query File is either by call number of the book or identification number of the user. The latter is used when producing lists of items out on loan to a borrower and in detecting delinquent borrowers. 


\section{OVERVIEW}

Comparison of statistics between FY 1969/70 and FY 1971/72 showed a 12 percent increase in circulation. During the same period there was a 61 percent increase in the number of people using the library. The Circulation Department has been able to handle the increased workload more efficiently because of the automated system. A decrease in clerical time required for carrying out the tasks of the department has been realized. The circulation records are now updated five times per week and notices are issued promptly. Previously, updating was possible only once in every seven to ten days. Service to the user is much faster and more accurate in charging books and in providing information on this status. Control of items loaned to users is more effective. Information for management of the collection and provision of improved service is available.

System disadvantages are related to the mode of data input and lack of author and title information on records. Transcription errors occur during manual capture of data at the time the transaction occurs and when the data are entered by the clerical staff from the terminal. Correction of errors requires rekeying and reentry of the corrected data for reprocessing. This increases cost in terms of personnel time and equipment use.

Author and title information is not provided in the Query File or on notices sent to users. This is an inconvenience to the user and requires checking of the shelf list by library personnel to provide the information when required. These potential disadvantages were recognized at the time the system was planned. However, they were not considered serious drawbacks. The decision was made to adopt the system and, when additional funds were forthcoming, to provide machine readable input and add author and title information to the records.

\section{COSTS}

The cost of the system during its first year of operation was $\$ 10,590.65$. This included monthly charges for rental of equipment, use of ATS, storage of records, computer time, and print costs.

\begin{tabular}{|c|c|}
\hline IBM 2741 Terminal (including phone line) & $\$ 1082.86$ \\
\hline ATS sign on time & 1042.08 \\
\hline ATS storage & 3187.24 \\
\hline Computer time and print costs & 5278.47 \\
\hline Total & $\$ 10,590.65$ \\
\hline
\end{tabular}

Unit cost figures are imperfect, but over 69,000 transactions were processed and over 20,000 notices generated at an average unit cost of 11.6 cents. Clerical time is not included in this figure. The number of clerical assistants remained constant although, as noted, all phases of the work of the Circulation Department increased. 


\section{FUTURE DEVELOPMENT}

In the future, the library hopes to be able to take greater advantage of the on-line query capability of the present system. Additional IBM 2741 terminals at selected locations in the library could provide instantaneous file query. While non-routine queries are made on-line, the library now uses printed listings for most routine queries.

The installation of automatic data input devices, such as IBM 1030 equipment, would permit reading of coded book cards and patron identification cards with direct transmission of data to ATS storage. The hardware and software modification required to implement this additional capability is technically feasible and not financially prohibitive.

The present system is to be installed soon in another library on the SUNYAB campus. Implementation should require only minimal software modifications to identify and keep separate the records of the other library. Adoption is simplified because of the fact that book cards are not required and that the circulation file consists only of charged materials and not a record of complete library holdings.

\section{ACKNOWLEDGMENTS}

The following individuals contributed their varied talents and support to the development and implementation of the system: Mr. Erich Meyerhoff, former librarian of the Health Sciences Library; Gerald Lazorick, systems design programmer, former director, Technical Information Dissemination Bureau, SUNYAB; Mrs. Jean Risley, programmer/analyst; Mr. Mark Fennessy, former library intern at the Health Sciences Library; and the clerical staff of the Circulation Department, especially Barbara Helminiak and Evelyn Hufford. 